\title{
SINTESA EKSPRESI WAJAH KARAKTER VIRTUAL 3D MENGGUNAKAN ACTION UNIT BERBASIS FACIAL ACTION CODING SYSTEM
}

\author{
${ }^{1}$ Matahari Bhakti Nendya, ${ }^{2}$ Lailatul Husniah, ${ }^{3}$ Hardianto Wibowo, ${ }^{4}$ Eko Mulyanto Yuniarno \\ ${ }^{1}$ Program Studi Informatika, Fakultas Teknologi Informasi, Universitas Kristen Duta Wacana \\ ${ }^{2,3}$ Program Studi Teknik Informatika, Fakultas Teknik, Universitas Muhammadiyah Malang \\ ${ }^{4}$ Departemen Teknik Komputer, Fakultas Teknologi Elektro dan Informatika Cerdas, Institut Teknologi \\ Sepuluh Nopember \\ 11didanendya@ti.ukdw.ac.id, ${ }^{2 h u s n i a h @ u m m . a c . i d, ~}{ }^{3}$ ardi@umm.ac.id, ${ }^{4}$ ekomulyanto@its.ac.id
}

\begin{abstract}
Abstrak
Proses pembentukan ekspresi wajah pada karakter virtual 3D merupakan pekerjaan panjang dengan tingkat kesulitan yang tinggi. Ekspresi wajah sendiri merupakan kunci dari proses karakter virtual 3D tampak hidup. Penelitian ini dilakukan untuk mendapatkan ekspresi wajah dengan menggabungkan beberapa Action Unit yang ada pada FACS dan diimplementasikan pada wajah karakter virtual 3D. Action Unit pada FACS dipilih karena mengacu pada struktur otot wajah manusia.

Eksperimen yang dilakukan menghasilkan komninasi Action Unit yang dapat membentuk ekspresi seperti joy expression yang dihasilkan dari kombinasi AU 12+26, dan surprise expression yang dihasilkan dari kombinasi AU $-4+5+26$. Sedangkan untuk sadness expression dan disgust expression karena ada AU yang tidak terwakili pada model 3D sehingga di dapatkan hasil ekspresi yang kurang maksimal.
\end{abstract}

Kata kunci: karakter virtual 3D, ekspresi wajah, action unit dan FACS

\begin{abstract}
The process of facial expressions on 3D virtual characters is a long job with a high level of difficulty. Facial expression itself is the key to the process of virtual $3 D$ characters appearing alive. This research was conducted for facial expressions by combining several Action Units in FACS and implementing them on the faces of $3 D$ virtual characters. The action unit in FACS was chosen because it refers to the muscle structure of the human face.

The experiments carried out resulted in a combination of Action Units which could form expressions such as joy expressions generated from a combination of $A U 12+26$, and surprise expressions generated from a combination of $A U-4+5+26$. Meanwhile, for sadness expression and disgust expression, AU not represented in the $3 D$ model, so results of the expression are less than optimal.
\end{abstract}

Keywords: 3D virtual character, facial expression, action unit and FACS 


\section{Pendahuluan}

Ekspresi wajah didapatkan dari gerakan wajah yang terjadi karena otot-otot wajah yang bergerak. Gerakan-gerakan wajah manusia memiliki peranan penting saat tatap muka dan berkomunikasi. Ekspresi wajah merupakan sesuatu yang paling alami, kuat dan memiliki arti tersendiri bagi manusia yang digunakan untuk berkomunikasi dan menyampaikan niat mereka (Tian, Kanade, \& Cohn, 2000). Ekspresi wajah juga mampu menggambarkan emosi dan suasana hati dan dapat menyampaikan informasi tentang kepribadian atau karakteristik seseorang (The Duy Bui, 2004). Beberapa penelitian dilakukan di bidang animasi termasuk animasi gerak wajah dan untuk mendapatkan ekspresi wajah.

Teknik lain untuk membentuk animasi gerak wajah dapat menggunakan Feature Point Cluster, dimana titik fitur wajah dikelompokkan sesuai dengan titik fitur wajah yang mewakili otot gerak wajah (Nendya \& Gunanto, 2014). Teknik blendshapes digunakan dengan cara membentuk geometri model wajah yang sama dengan ekspresi netral. Teknik ini membutuhkan lebih dari 100 shapes untuk dapat membentuk ekspresi wajah yang kompleks. Kelemahan dari teknik blendshapes ini dapat diatasi dengan menggunakan teknik transfer animasi dari model sumber animasi seperti motion capture ke model karakter 3D yang digunakan. (Orvalho, Zacur, \& Susin, 2008). Dari animasi gerak wajah tersebut didapatkan beberapa ekspresi wajah seperti senang, marah atau sedih.

Facial Action Coding System (FACS) digunakan untuk menggambarkan ekspresi wajah oleh Action Unit ( $A U$ ) yang berkorelasi dengan ekspresi wajah. FACS menetapkan $44 A U$ dengan $30 A U$ yang terkait secara anatomi dengan kontraksi otot-otot wajah. Pada wajah bagian atas ada $12 A U$ dan wajah bagian bawah ada $18 A U$. Model $A U$ dalam FACS sendiri dapat digunakan tunggal atau dilakukan kombinasi dengan $A U$ lainnya. (Ekman, P; Friesen, 1972). FACS membantu dalam memberikan deskripsi yang diperlukan sebagai penjelasan mengenai detail ekspresi wajah. (Tian et al., 2000). Penelitian ini mengusulkan sebuah metode untuk mendapatkan ekspresi wajah yang diinginkan pada model wajah $3 D$ dengan mencoba mengkombinasikan beberapa Action Unit yang ada pada $F A C S$. 


\section{Ekspresi Wajah Manusia}

Ekspresi wajah merupakan salah satu bentuk komunikasi non verbal dan dapat menyampaikan keadaan emosi dari seseorang kepada orang yang mengamatinya. Ekspresi wajah terebentuk dari hasil gerakan otot pada wajah. Ada enam emosi dasar yaitu sedih, gembira, marah, takut, jijik dan terkejut. (Sumpeno, Hariadi, \& Purnomo, 2011)

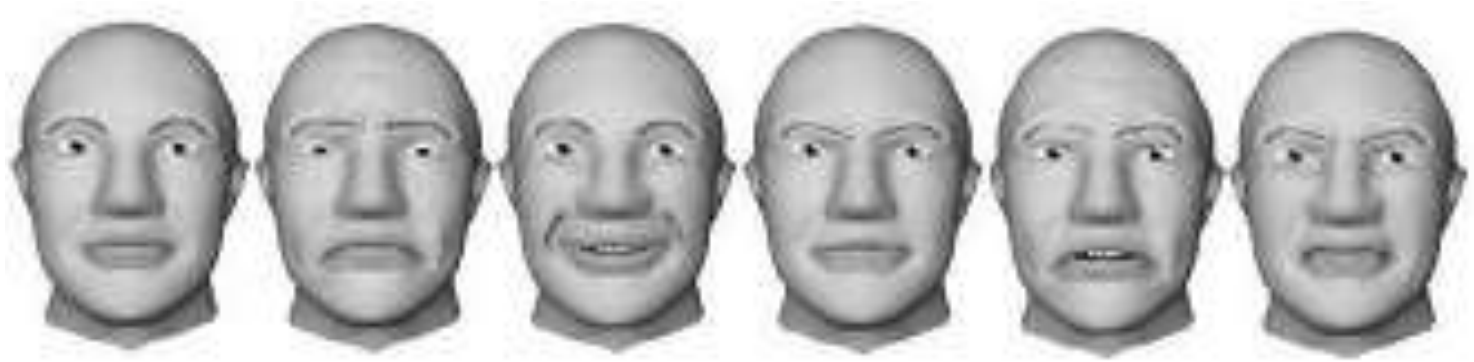

Gambar 1 Ekspresi wajah netral dan emosi dasar: sedih, senang, gembira, marah, takut, jijik dan terkejut. (dari kiri ke kanan) (The Duy Bui, 2004)

Model ekspresi wajah kemudian perlu dibuat deskripsinya supaya lebih mudah dalam melakukan implementasi bentuk ekspresi wajah pada model 3D. Pada tabel 1 disajikan bentuk deskripsi dari ekspresi wajah berdasarakan Gambar 1 .

Tabel 1 Deskripsi Ekspresi Wajah Pada Emosi Dasar (The Duy Bui, 2004)

\begin{tabular}{|c|l|l|}
\hline No & Ekspresi dasar & \multicolumn{1}{c|}{ Deskripsi tekstual dasar pada wajah } \\
\hline 1 & Senang & $\begin{array}{l}\text { Posisi mulut terbuka. } \\
\text { Posisi sudut-sudut pada mulut ditarik menuju telinga. } \\
\text { Posisi alis normal }\end{array}$ \\
\hline 2 & Sedih & $\begin{array}{l}\text { Posis alis bagian dalam bengkok ke arah atas. } \\
\text { Posisi mata sedikit tertutup. } \\
\text { posisi mulut santai. }\end{array}$ \\
\hline 3 & Takut & $\begin{array}{l}\text { Posisi alis terangkat dan ditarik keduanya. } \\
\text { Posisi alis bagian dalam bengkok kearah atas. } \\
\text { Bentuk mata cenderung tegang. }\end{array}$ \\
\hline 4 & Marah & $\begin{array}{l}\text { Posisi alis bagian dalam ditarik bersama ke bagian bawah. } \\
\text { Posisi mata terbuka lebar. }\end{array}$ \\
\hline
\end{tabular}




\begin{tabular}{|c|l|l|}
\hline No & Ekspresi dasar & \multicolumn{1}{c|}{ Deskripsi tekstual dasar pada wajah } \\
\hline 5 & Jijik & $\begin{array}{l}\text { Posisi bibir atas cenderung naik dan asismeteris. } \\
\text { Kondisi alis dan kelopak mata cenderung rileks. }\end{array}$ \\
\hline 6 & Terkejut & $\begin{array}{l}\text { Posisi kelopak mata atas terbuka lebar. } \\
\text { Posisi kelopak mata bawah santai. } \\
\text { Posisi rahang terbuka. } \\
\text { Posisi alis naik. }\end{array}$ \\
\hline
\end{tabular}

\section{Facial Action Coding System}

Facial Action Coding System (FACS) meruapakan sistem pengkodean ekspresi wajah berdasarkan aktivitas otot wajah tertentu dimana aktivitas otot tersebut memberikan informasi mengenai emosi wajah berdasarkan ekspresi yang dihasilkan (Gavrilescu, 2014). Satu set Action Unit ( $A U$ ) memiliki sifat aditif dan non aditif yang mewaliki setiap gerakan wajah. $A U$ dikatakan aditif jika masing-masing $A U$ merupakan $A U$ independent, sedangkan $A U$ dikatakan non-aditif jika terjadi modifikasi antar $A U$. FACS memiliki 44 AU. Ekman menyatakan lebih dari 7000 kombinasi $A U$ yang telah diamati.(Gavrilescu, 2014).

Penelitian ini menggunakan beberapa $A U$ yang mewakili otot wajah dan digerakan oleh nervus facialis atau nervus VII. Teradapat 10 Action Unit yang dikombinasikan untuk menghasilkan beberapa ekspresi wajah seperti yang terlihat pada tabel 2.

Tabel 2 Kombinasi Action Unit yang menghasilan ekspresi wajah

\begin{tabular}{|c|l|c|c|}
\hline $\begin{array}{c}\text { Action } \\
\text { Unit }\end{array}$ & \multicolumn{1}{c|}{ Deskripsi } & Otot Wajah & Contoh Gambar \\
\hline 0 & $\begin{array}{l}\text { Wajah Netral } \\
\text { mata, alis, pipi dan bibir dalam } \\
\text { kondisi rileks dan bibir tertutup }\end{array}$ & frontalis, pars medialis & \\
\hline 1 & Posisi alis bagian dalam naik & & \\
\hline
\end{tabular}




\begin{tabular}{|c|c|c|c|}
\hline $\begin{array}{c}\text { Action } \\
\text { Unit }\end{array}$ & Deskripsi & Otot Wajah & Contoh Gambar \\
\hline 2 & Posisi alis bagian luar naik. & frontalis, pars lateralis & \\
\hline 4 & $\begin{array}{l}\text { Posisi alis turun dan ditarik ke } \\
\text { bawah bersama. }\end{array}$ & $\begin{array}{l}\text { depressor supercilii, } \\
\text { corrugator supercilii }\end{array}$ & \\
\hline 5 & Posisi kelopak mata atas naik & $\begin{array}{l}\text { levator palpebrae } \\
\text { superioris }\end{array}$ & \\
\hline 7 & Posisi kelopak mata bawah naik & $\begin{array}{l}\text { orbicularis oculi, pars } \\
\text { palpebralis }\end{array}$ & \\
\hline 12 & Posisi ujung bibir ditarik & zygomaticus major & \\
\hline 15 & $\begin{array}{l}\text { Posisi ujung bibir ditarik ke } \\
\text { bawah }\end{array}$ & $\begin{array}{l}\text { depressor anguli oris (also } \\
\text { known as triangularis) }\end{array}$ & \\
\hline 26 & Posisi rahang ditarik ke bawah & $\begin{array}{l}\text { masseter; relaxed } \\
\text { temporalis and internal } \\
\text { pterygoid }\end{array}$ & \\
\hline
\end{tabular}




\section{Metodologi Penelitian}

Eksperimen dilakukan untuk mengetahui hasil akhir bentuk ekspresi yang dihasilkan dari kombinasi Action Unit. Hal pertama yang dilakukan dalam membuat model atau karakter wajah 3D lengkap dengan rigging sebagai kontrol untuk menggerakan wajah dengan Action Unit. Gambar 2 merupakan metodologi penelitian yang digunakan.

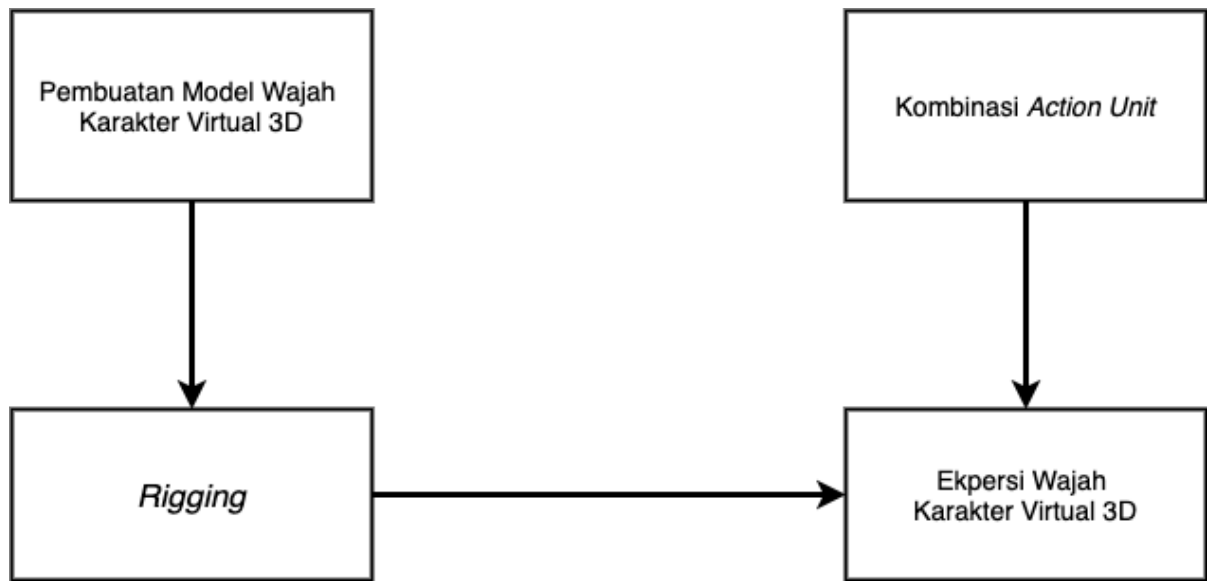

Gambar 2 Metodologi Penelitian Sintesa Ekspresi Wajah Karakter Virtual 3D menggunakan Action Unit Berbasis Facial Action Coding System (FACS)

Model karakter virtual 3D yang digunakan pada penelitian ini adalah model wajah netral atau tanpa ekspresi dan kemudian ditentukan beberapa Action Unit yang sesuai dengan tabel 2.

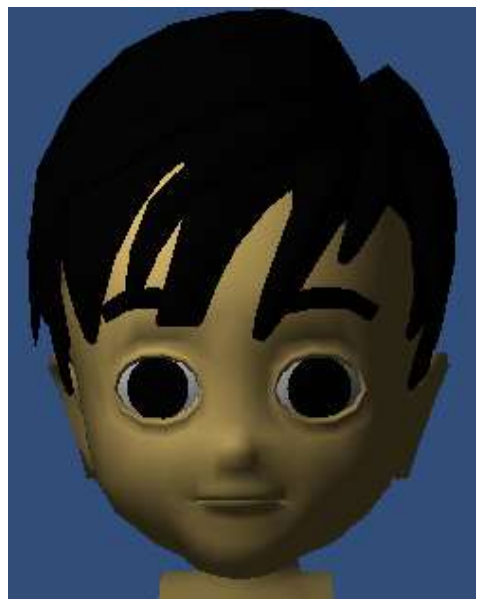

Gambar 3 Model Wajah 3D Ekspresi Netral 
Dari 8 Action Unit yang dipilih dikelompokkan menjadi dua bagian yaitu bagian wajah atas yang meliputi bagian alis dan mata, serta bagian wajah bawah yang meliputi bagian bibir dan dagu. Kombinasi $A U$ yang pertama adalah mengkombinasikan $A U$ yang berada pada tabel itu sendiri dan kombinasi $A U$ antar tabel. Dimana hasil kombinasi $A U$ tersebut akan diterapkan pada model wajah 3D yang kemudian hasilnya akan dibandingkan dengan ekspresi wajah hasil generate dari software FaceGen yang mengacu pada tabel 2.

Tabel 3 Action Unit Bagian Wajah Atas

\begin{tabular}{|c|c|c|}
\hline Action Unit & Contoh Gambar & Model Wajah 3D \\
\hline 1 & & \\
\hline 2 & & \\
\hline 4 & . & \\
\hline 5 & (9) & \\
\hline 7 & & \\
\hline
\end{tabular}

Tabel 3 merupakan Action Unit bagian atas wajah yang lebih berfokus pada pergerakan mata, alis, dan kelopak mata. Model wajah 3D disamakan bentuknya dengan model acuan kemudian akan dikombinasikan dengan AU yang lain untuk dihitung model pergerakan dan perindahan AU yang terjadi. 
Tabel 4 Action Unit Bagian Wajah Bawah

\begin{tabular}{|c|c|c|}
\hline Actioin Unit & Contoh Gambar & Model Wajah 3D \\
\hline 12 & & \\
\hline 15 & & \\
\hline
\end{tabular}

Tabel 4 merupakan Action Unit bagian bawah wajah yang lebih berfokus pada pergerakan hidung, mulu, bibir, dan rahang. Model wajah $3 D$ disamakan bentuknya dengan model acuan kemudian akan dikombinasikan dengan $A U$ yang lain untuk dihitung model pergerakan dan perindahan $A U$ yang terjadi.

\section{Hasil dan Pembahasan}

Pada penelitian ini kombinasi Action Unit tidak memperhatikan urutan dan setiap Action Unit hanya dapat dipilih satu kali. Jumlah kombinasi $A U$, dapat ditentukan dengan menggunaakan rumus (1).

$$
\frac{n !}{a !(n-a) !}=\left(\begin{array}{l}
n \\
a
\end{array}\right)
$$

n adalah jumlah $A U$ yang dapat dipilih dan a adalah jumlah $A U$ yang harus dipilih. Untuk mengkombinasikan $A U$ pada tabel 4 dan 5 digunakan rumus kombinasi tanpa perulangan (1), sehingga dihasilkan total kombinasi $A U$ sebanyak 28 kombinasi dengan jumlah $A U$ ada 2 untuk masing-masing kombinasi. untuk tabel 4 dihasilkan kombinasi $A U$ sebanyak 10 kombinasi antar $A U$ dalam tabel 3 dan untuk tabel 4 dihasilkan $A U$ sebanyak 3 kombinasi antar $A U$ dalam tabel 4. Sisanya adalah kombinasi $A U$ antar tabel sebanyak 15 kombinasi. 
Tabel 5 Kombinasi Action Unit Penyusun Ekspresi

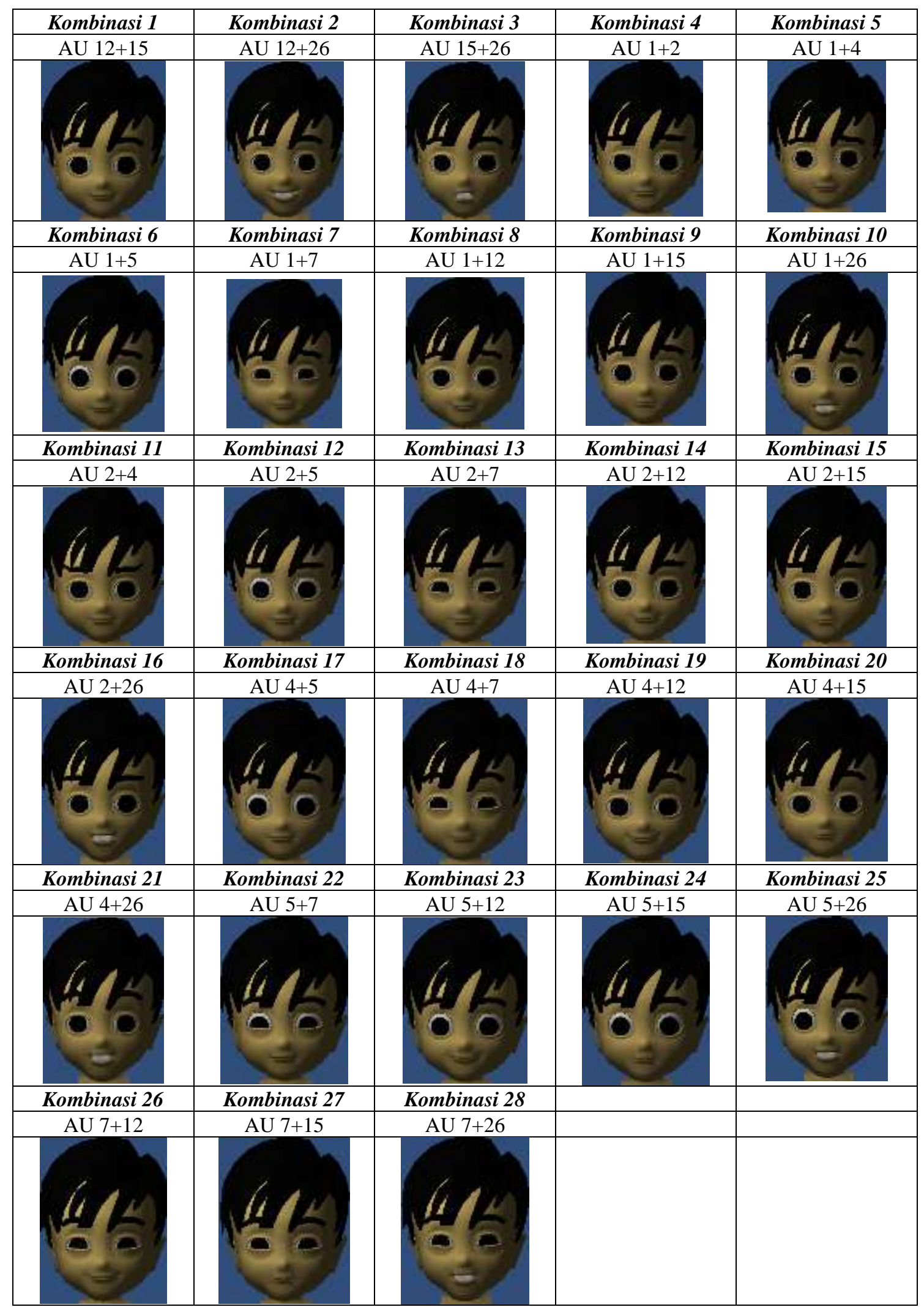


Percobaan selanjutnya adalah kombinasi Action Unit sesuai dengan deskripsi pada tabel 2. Sehingga jumlah Action Unit yang dikombinasikan bisa lebih dari 2 Action Unit untuk masing-masing kombinasi.

Tabel 6 Kombinasi Action Unit dengan Ekpresi Dasar

\begin{tabular}{|c|c|c|c|}
\hline $\begin{array}{c}\text { Ekspresi } \\
\text { Dasar }\end{array}$ & Deskripsi tekstual dasar pada wajah & $\boldsymbol{A U}$ & Gambar model wajah $3 D$ \\
\hline \multirow{3}{*}{ Senang } & 1. Posisi alis normal. & 12 & \\
\hline & $\begin{array}{l}\text { 2. Posisi mulut terbuka. } \\
\text { 3. Posisi sudut-sudut pada mulut ditarik menuju } \\
\text { telinga. }\end{array}$ & 26 & \\
\hline & 4. Kombinasi $A U$ & $12+26$ & \\
\hline \multirow{4}{*}{ Sedih } & $\begin{array}{l}\text { 1. Posisi alis bagian dalam bengkok ke arah } \\
\text { atas. }\end{array}$ & 1 & \\
\hline & 2. Posisi mata sedikit tertutup. & - & \\
\hline & 3. Posisi mulut santai. & 0 & \\
\hline & 4. Kombinasi $A U$ & $0+1$ & \\
\hline \multirow{4}{*}{ Takut } & 1. Posisi alis terangkat dan ditarik keduanya. & 2 & \\
\hline & $\begin{array}{l}\text { 2. Posisi alis bagian dalam bengkok ke arah } \\
\text { atas. }\end{array}$ & 1 & \\
\hline & 3. Bentuk mata cenderung tegang & 5 & \\
\hline & 4. Kombinasi $A U$ & $1+2+5$ & \\
\hline \multirow{4}{*}{ Marah } & $\begin{array}{l}\text { 1. Posisi alis bagian dalam ditarik bersama ke } \\
\text { bagian bawah. }\end{array}$ & -1 & \\
\hline & 2. Posisi mata terbuka lebar. & 5 & \\
\hline & $\begin{array}{l}\text { 3. Posisi bibir ditekan satu sama lain dan } \\
\text { menampilkan gigi. }\end{array}$ & 15 & \\
\hline & 4. Kombinasi $A U$ & $\begin{array}{l}-1+5 \\
+15\end{array}$ & \\
\hline \multirow{3}{*}{ Jijik } & $\begin{array}{l}\text { 1. Posisi bibir atas cenderung naik dan } \\
\text { asismeteri. }\end{array}$ & 0 & \\
\hline & $\begin{array}{l}\text { 2. Kondisi alis dan kelopak mata cenderung } \\
\text { rileks. }\end{array}$ & - & \\
\hline & 3. Kombinasi $A U$ & - & \\
\hline \multirow{3}{*}{ Terkejut } & 1. Posisi kelopak mata atas terbuka lebar. & -4 & \\
\hline & $\begin{array}{l}\text { 2. Posisi kelopak mata bawah santai. } \\
\text { 3. Pisisi alis naik }\end{array}$ & 5 & \\
\hline & 4. Posisi rahang terbuka. & 26 & \\
\hline
\end{tabular}




\begin{tabular}{|c|c|c|c|}
\hline $\begin{array}{c}\text { Ekspresi } \\
\text { Dasar }\end{array}$ & Deskripsi tekstual dasar pada wajah & AU & Gambar model wajah 3D \\
\hline & & & $-4+5+$ \\
& 5. Kombinasi $A U$ & 26 & \\
\hline
\end{tabular}

Pada penelitian ini didefinisikan $A U-1$ dan $A U-4$ yang diartikan sebagai negasi atau kebalikan dari $A U 1$ dan $A U$ 4, karena pada FACS tidak didefinisikan $A U$ yang mewakili (negasi 1/-1 ambingu dengan $A U$ 4). Dari percobaan atau eksperimen yang telah dilakukan dan ditunjukkan oleh tabel 5 dan tabel 6 untuk kombinasi 2 AU 12+26 dihasilkan joy expression. Untuk sadness expression dan disgust expression tidak didapatkan hasil yang maksimal karena ada $A U$ yang belum diimplemetasikan pada model 3D. Surprise expression dihasilkan dari kombinasi $A U-4+5+26$, dimana AU -4 artinya adalah negasi dari $A U$ 4. Ada 2 kombinasi $A U$ yang jika dikombinasikan menghasilkan wajah netral yaitu kombinasi 1 yang mengkombinasikan $A U 12+15$, yang mana $A U 12$ adalah menarik ujung bibir ke atas sedangkan $A U 15$ menarik ujung bibir ke bawah sehingga didapatkan nilai tengah atau rata-rata dari penggabungan kedua $A U$ tersebut yang diartikan tidak ada perubahan pada ujung bibir.

\section{Kesimpulan}

Sintesa ekspresi menggunakan Action Unit $(A U)$ yang mengacu pada FACS dapat digunakan untuk menghasilkan ekspresi wajah pada model 3D. Dimana beberapa kombinasi $A U$ dapat menghasilkan ekspresi yang diinginkan seperti joy expression yang dihasilkan dari kombinasi $A U 12+26$, dan surprise expression yang dihasilkan dari kombinasi $A U-4+5+26$. Sadness expression dan disgust expression adalah ekspresi karena ada $A U$ yang tidak terwakili pada model $3 D$ sehingga didapatkan hasil ekspresi yang kurang maksimal. Ekspresi yang tepat ke depannya didapatkan dengan menambahkan jumlah titik kontrol pada wajah agar dapat mewakili beberapa $A U$ yang belum dipilih untuk uji coba pada penelitian ini. 


\section{Referensi}

Ekman, P; Friesen, W. (1972). The Facial Action Coding System: A Technique For The Measurement of Facial Movement. San Fransisco: Consulting Psychologists Press, Inc.

Gavrilescu, M. (2014). Proposed architecture of a fully integrated modular neural network-based automatic facial emotion recognition system based on facial action coding system. IEEE International Conference on Communications. https://doi.org/10.1109/ICComm.2014.6866754

Nendya, M. B., \& Gunanto, S. G. (2014). ANIMASI EKSPRESI WAJAH PADA AVATAR BERBASIS FEATURE- POINT CLUSTER B-86 B-87. Prosiding SENTIA 2014-Politeknik Negeri Malang, 6, 86-90.

Orvalho, V. C., Zacur, E., \& Susin, A. (2008). Transferring the rig and animations from a character to different face models. Computer Graphics Forum, 27(8), 19972012. https://doi.org/10.1111/j.1467-8659.2008.01187.x

Parke, F. I. (1972). Computer generated animation of face. Proceedings of the ACM Annual Conference, 1, 451-457.

Sumpeno, S., Hariadi, M., \& Purnomo, M. H. (2011). Facial emotional expressions of life-like character based on text classifier and fuzzy logic. IAENG International Journal of Computer Science, 38(2), 122-133.

The Duy Bui. (2004). CREATING EMOTIONS AND FACIAL EXPRESSIONS. University of Twente.

Tian, Y. li, Kanade, T., \& Cohn, J. F. (2000). Recognizing upper face action units for facial expression analysis. Proceedings of the IEEE Computer Society Conference on Computer Vision and Pattern Recognition, 1(2), 294-301. https://doi.org/10.1109/cvpr.2000.855832 